\title{
FENOLOGIA DE CULTIVARES DE COQUEIRO-ANÃO NOS TABULEIROS COSTEIROS DE SERGIPE ${ }^{1}$
}

\author{
CÍNTIAPASSOS CASTRO², EDSON EDUARDO MELO PASSOS ${ }^{3}$, WILSON MENEZES ARAGÃO ${ }^{4}$
}

RESUMO - A fenologia do coqueiro fornece informações que tornam possível a seleção de cultivares a partir de características que permitam maior eficiência no uso do ambiente, tornando seu comportamento previsível em diversas condições. Dessa forma, analisou-se a fenologia de cultivares de coqueiro-anão nas condições edafoclimáticas dos tabuleiros costeiros do norte de Sergipe. O experimento foi conduzido em um plantio comercial da empresa Agreste no delineamento experimental em blocos ao acaso, com quatro tratamentos e quatro repetições, utilizando-se de oito plantas úteis por parcela. Foram avaliadas quatro cultivares de coqueiro-anão: anão amarelo da Malásia (AAM), anão vermelho da Malásia (AVM), anão vermelho de Camarões (AVC) e anão verde do Brasil de Jiqui (AVeBrJ) quanto ao número de folhas vivas (NFV), folhas emitidas (NFE) e folhas mortas (NFM), número de inflorescências emitidas (NIE), flores femininas por inflorescência (NFFI), frutos com três (NFr3) e seis meses (NFr6) de idade. A análise de variância foi realizada pelo programa Sisvar, versão 4.3 (InstallShield Corporation, Inc. Lavras, MG) e baseou-se nas médias das cultivares para cada característica, submetidas ao teste Tukey, a $5 \%$ de probabilidade. Na maior parte do período estudado, o AAM apresentou o maior NFV, enquanto o AVC, o menor. A cultivar AVeBrJ apresentou superioridade em relação a caracteres reprodutivos, como NFFI e NFr6. A partir dos resultados, conclui-se que o AVeBrJ é a cultivar mais adaptada às condições do Platô de Neópolis -SE.

Termos para indexação: Cocos nucifera $\mathrm{L}$., crescimento, floração, frutificação.

\section{THE PHENOLOGY OF DWARF COCONUT CULTIVARS IN NORTH OF SERGIPE COASTAL TABLELANDS}

\begin{abstract}
The phenology of coconut palms provides information which makes cultivars selection possible, due to characteristics that allow greater efficiency in environmental use, making its behavior predictable in any conditions. For this reason, the phenology of dwarf coconut palms was studied in the north of Sergipe coastal tablelands. The experiment was carried out at the Agreste commercial plantation, at a randomized block design with four treatments and four replications using eight plants per plot. The studied dwarf coconut cultivars were: the Malayan Yellow Dwarf (MYD), the Malayan Red Dwarf (MRD), the Cameroon Red Dwarf (CRD) and the 'Green Dwarf of Jiqui' (BGDJ) regarding the number of alive leaves (NAL), number of emitted leaves (NEL) and the number of dead leaves (NDL); number of emitted inflorescences (NEI), female flowers per inflorescence (NFFI), fruits at three (NFr3) and six (NrF6) months old, fruit weight and fruit water volume. The data were submitted to analysis of variance, which was made by Sisvar program, 4.3 version (InstallShield Corporation, Inc. Lavras, MG). The analysis was based on the cultivars averages concerning each characteristic and then, submitted to the test of Tukey at $5 \%$ of probability. During most of our research period, the MYD showed the greatest NAL, while the CRD, the smallest. The BGDJ has showed superiority in relation to reproductive characters such as NFFI and NFr6. Results have shown the BGDJ is the most adaptive cultivar to Platô de Neópolis-SE conditions.
\end{abstract}

Index terms: Cocos nucifera L., growth, flowering, frutification.

'(Trabalho 053-08). Recebido em: 10-03-2008. Aceito para publicação em: 08-10-2008.

${ }^{2}$ Bióloga, Mestre em Agroecossistemas do Núcleo de Pós-graduação e Estudos em Recursos Naturais-Neren. Universidade Federal de Sergipe (UFS), Aracaju-SE. E-mail: cintia_pas@hotmail.com

${ }^{3}$ Pesquisador Embrapa Tabuleiros Costeiros, CP 44 CEP 49025-040, Aracaju-SE. E-mail: edson@cpatc.embrapa.br

${ }^{4}$ Pesquisador Embrapa Tabuleiros Costeiros, CP 44 CEP 49025-040, Aracaju-SE. E-mail: aragaowm@cpatc.embrapa.br 


\section{INTRODUÇÃO}

O cultivo do coqueiro (Cocos nucifera L.) nos tabuleiros costeiros do norte de Sergipe ocorre em virtude de projeto de fomento público, o qual permitiu a interiorização dessa cultura normalmente cultivada na planície litorânea do Nordeste do Brasil. Neste projeto, são desenvolvidas ações da PIF (Produção Integrada de Frutas) coco, por incentivo do Ministério da Agricultura, Pecuária e Abastecimento (MAPA), que procura aliar na produção de frutíferas, a qualidade do produto e a sustentabilidade da exploração.

Entretanto, para que a PIF do coco seja desenvolvida adequadamente, há a necessidade de um conhecimento detalhado sobre a fenologia do coqueiro. A fenologia consiste no estudo do comportamento dos vegetais em relação ao meio ambiente, abrangendo padrões de folhação, floração e frutificação (Wood \& Burley, 1991), possibilitando assim o desenvolvimento de técnicas de manejo condizentes com as limitações ambientais existentes, seleção de cultivares mais adaptadas, maximização do retorno financeiro e garantia da sustentabilidade.

O melhoramento de plantas procura reunir um conjunto de características desejáveis em um único indivíduo, e o conhecimento dessas características é possível por meio da fenologia. Segundo World Bank (1991), o objetivo do melhoramento é desenvolver novas cultivares mais produtivas, adaptadas às condições ambientais desfavoráveis e a sistemas de produção com baixa utilização de insumos.

É necessário conhecer a fenologia do coqueiro para melhor compreensão dos efeitos causados pelas diferentes condições de cada agroecossistema. Condições desfavoráveis, como estiagens prolongadas, por exemplo, causam redução do ritmo de emissão foliar e do tempo de vida da folha (Passos, 1998), além de provocar aumento no índice de abortamento de flores femininas (Fremond et al., 1975). Segundo Persley (1992), a emissão de folhas é controlada pela idade e vigor da planta, pela cultivar e pelas condições do meio ambiente. A quantidade de folhas emitidas reflete diretamente no crescimento e na produção do coqueiro, pois na axila de cada folha emitida existe um primórdio floral que se transformará em inflorescência; isso não ocorre quando as condições ambientais são muito severas. Desse modo, a produção de folhas é um dos referenciais para se avaliar o potencial das cultivares (Silva et al., 2004).

O conhecimento da fenologia do coqueiro também é uma fonte importante de resultados para a sustentabilidade ambiental, uma vez que auxiliam no entendimento de diversos aspectos envolvidos com o manejo planta-água-solo, como, por exemplo, aplicação adequada de água e nutrientes.

Dessa forma, o presente trabalho objetivou analisar o comportamento vegetativo e reprodutivo de cultivares de coqueiro-anão, nas condições edafoclimáticas dos tabuleiros costeiros do norte de Sergipe.

\section{MATERIAL E MÉTODOS}

O experimento foi conduzido em um plantio comercial da empresa Agreste, localizado no município de Neópolis, Sergipe (10 $\left.10^{\circ} 16^{\prime} \mathrm{S}, 36^{\circ} 5^{\prime} \mathrm{W}\right)$, altitude de $75 \mathrm{~m}$. O clima da região, segundo a classificação de Köeppen, é do tipo A’s (tropical chuvoso com verão seco). A pluviosidade média anual é de $1.200 \mathrm{~mm}$, sendo que $80 \%$ dela ocorre entre os meses de abril e setembro. Os dados de pluviosidade (Figura 1), durante a condução do experimento e nos dois anos anteriores ao início das avaliações, foram obtidos na estação meteorológica da Associação dos Condôminos do Distrito de Irrigação do Platô de Neópolis (ASCONDIR).

O solo da área experimental é classificado como Argissolo Amarelo Distrófico, de baixa fertilidade natural. Sua composição química na camada de 0-20 cm, segundo o Instituto Tecnológico e de Pesquisas do Estado de Sergipe (ITPS), está apresentada na Tabela 1 .

O delineamento experimental foi em blocos ao acaso, com quatro tratamentos (cultivares) e quatro repetições, com oito plantas úteis por parcela. As cultivares de coqueiro avaliadas foram: anão amarelo da Malásia (AAM), anão vermelho da Malásia (AVM), anão vermelho de Camarões (AVC), e anão verde do Brasil de Jiqui (AVeBrJ), com 6 anos de idade, plantadas em espaçamento de 7,5 $\mathrm{m} \mathrm{x} \mathrm{7,5}$ $\mathrm{m}$, em triângulo eqüilátero.

A quantidade de água aplicada pelo sistema de microaspersão variou de 70 a $150 \mathrm{~L}$ por dia, a depender da pluviosidade do período. A adubação foi efetuada tomando como base os dados foliares realizados anualmente no laboratório de fertilidade da Embrapa Tabuleiros Costeiros, que , também, recomendava os níveis de adubação aplicados.

A fenologia do coqueiro foi estudada por meio de avaliações trimestrais dos seguintes caracteres: número de folhas vivas (NFV), número de folhas emitidas (NFE), número de folhas mortas (NFM), número de inflorescências emitidas (NIE), número de flores femininas por inflorescência (NFFI), número de frutos com três meses (NFr3) e número 
de frutos com seis meses (NFr6) de idade.

Foi realizada análise de variância, utilizandose do programa Sisvar, versão 4.3, (InstallShield Corporation, Inc. Lavras, MG). As médias obtidas foram comparadas pelo teste Tukey, a 5\% de probabilidade

\section{RESULTADOS E DISCUSSÃO}

O número de folhas vivas nas cultivares avaliadas variou de 18 a 27 (Tabela 2), o que evidencia o bom aspecto vegetativo das plantas em estudo, considerando que o coqueiro-anão cultivado em condições ambientais satisfatórias apresenta copa com 25 a 28 folhas abertas, que permanecem vivas por um período de três a três anos e meio (Ohler, 1999).

Em todas as cultivares, o NFV foi menor no final da estação seca (dezembro a março), não havendo diferença significativa para esse caráter, entre esses dois meses, em três das quatro cultivares (Tabela 2). Embora março de 2003 tenha sido um mês atípico, com pluviosidade de 96,5 mm (Figura 1), essa antecipação no início das chuvas não foi suficiente para proporcionar aumento na emissão foliar mesmo que a morte de folhas tenha sido muito inferior em março, se comparada a dezembro (Tabela 3), contribuindo para a elevação do NFV em março, sendo essa diferença significativa no AAM (Tabela 2).

Durante o período experimental, o AAM apresentou o maior NFV (Tabela 2), não diferindo significativamente do AVM e AVeBrJ nos meses mais secos (dezembro e março). Embora essa cultivar mantenha uma copa com maior número de folhas durante quase todo o ano, mostrou-se sensível ao estresse hídrico provocado pelos meses secos, quando apresentou o maior NFM em dezembro, não diferindo apenas do AVM (Tabela 3).

Mesmo com maior perda de folhas que as demais cultivares durante os meses secos, o AAM manteve sua copa com maior NFV, indicando que essa cultivar responde de maneira mais eficiente a um período favorável de disponibilidade hídrica, com elevada emissão foliar, compensando o secamento mais rápido das folhas no final da estação seca. Passos et al. (1999), estudando o comportamento fisiológico de cultivares de coqueiro, observaram que o AAM apresenta elevado potencial fotossintético quando as condições ambientais são satisfatórias e regula gradualmente a condutância estomática sob condições de estresse hídrico.

$\mathrm{O}$ menor NFV no AVC deve-se à arquitetura da planta e ao seu ritmo de emissão foliar e não às respostas aos estresses ambientais, visto que ele tem menor emissão foliar durante todo o ano (Tabela 4), inclusive nos meses de pluviosidade satisfatória.

A emissão de folhas ocorreu durante todo o período estudado (Tabela 4), com cada planta emitindo, em média, 2,2 a 5,0 folhas por trimestre. A produção contínua de folhas é um evento comum nas palmeiras, conforme observado por Anderson et al. (1988), que estudaram os aspectos fenológicos do babaçu; Oliveira et al. (2003), que estudaram esses mesmos aspectos da palmeira tucumã, e Scariot et al. (1991), os da macaúba. Segundo Passos (1998), sob condições ambientais favoráveis, o coqueiro-anão pode emitir até 18 folhas por ano, enquanto Ohler (1999) considera 21 folhas a média anual de emissão. Os resultados deste trabalho mostram uma emissão foliar de até 18 folhas no período de um ano.

O maior NFE ocorreu em dezembro e junho (Tabela 4), meses seco e chuvoso, respectivamente (Figura 1), apresentando redução nos trimestres posteriores, quando todas as cultivares foram estatisticamente semelhantes. Esse fato ocorre devido o primórdio foliar diferenciar-se cerca de dois anos antes do aparecimento da lança - folha fechada no ápice do caule (Fremond et al., 1975), coincidindo com períodos de condições favoráveis ao desenvolvimento desse primórdio - dezembro/2000 (93,9 mm) e junho/2001 (459,3 mm) (Figura 1). Já a redução na emissão de folhas, em março de 2003 , pode ser explicada pelo período de baixíssima pluviosidade entre os meses de janeiro $(30,2 \mathrm{~mm}) \mathrm{e}$ fevereiro $(0,4 \mathrm{~mm})$ de 2001, que pode ter prejudicado a formação do primórdio da folha em consequiência do severo estresse hídrico.

A maior emissão foliar no período de setembro a dezembro coincide com a redução do NFV nesse último mês, o que pode ser explicado pela elevada taxa de morte das folhas nesse mesmo período (Tabela 3), causada por um período seco, a partir de setembro, quando a pluviosidade desse mês não atingiu $50 \mathrm{~mm}$, e muito seco entre outubro e dezembro, quando a pluviosidade em cada mês foi inferior a $10 \mathrm{~mm}$ (Figura 1). Considerando que o regime pluviométrico ideal para o coqueiro é caracterizado por uma precipitação anual de $1.500 \mathrm{~mm}$, com boa distribuição de chuvas durante o ano, o ideal seria pluviosidades mensais de $130 \mathrm{~mm}$ (Fremond et al.,1975). O coqueiro apresenta crescimento e produção prejudicados quando a pluviosidade mensal é inferior a $50 \mathrm{~mm}$ por um período de três meses consecutivos (Child, 1974), o que pode ser confirmado neste trabalho, onde se pode observar, nas Tabelas 2 e 3, o número elevado de folhas mortas, com redução do número de folhas vivas durante a 
seca de verão do Nordeste do Brasil. Embora o experimento tenha sido desenvolvido numa área irrigada, fica evidente que a irrigação não foi suficiente para impedir o estresse hídrico, uma vez que as aplicações não foram suficientes para compensar a perda de água da planta durante o período de alta demanda evaporativa. Esse indicador mostra a necessidade de controle eficiente da irrigação para que a planta não seja prejudicada.

A maior emissão de inflorescência ocorreu no período de dezembro a junho (Tabela 5), com mais de quatro inflorescências emitidas/trimestre, ou seja, uma inflorescência emitida a cada 20 dias aproximadamente. No trimestre seguinte (junho a setembro), ocorreu redução significativa no NIE, nas quatro cultivares, sendo que no AVC essa redução ocorreu a partir de março.

É importante observar, nas Tabelas 4 e 5, que a emissão de folhas e inflorescências não são idênticas, visto que a folha mais jovem emitida está no ápice do estipe, enquanto a inflorescência mais jovem, recém-aberta, está na axila da folha 9 ou 10 , que foi emitida há alguns meses; portanto, os números de emissões não são obrigatoriamente iguais. Como na axila de cada folha desenvolve-se um primórdio floral que se converterá em uma inflorescência frutífera, dependendo das condições de nutrição e clima (Ohler, 1999), o número de folhas emitidas anualmente é quase igual ao número de inflorescências emitidas (Tabelas 4 e 5). Sob severas condições de estresse hídrico e/ou nutricional, pode ocorrer abortamento da inflorescência, resultando em maior emissão de folhas sem inflorescências.

O maior NIE, nas quatro cultivares estudadas durante o período seco e final desse período (Figura 1 e Tabela 5), deve-se ao fato de o esboço floral terse formado cerca de 33 meses antes da abertura da inflorescência (Fremond et al., 1975), coincidindo com meses de pluviosidade: $74,5 \mathrm{~mm}$ (março de 2000) e 237,2 mm (junho de 2000), dando à planta boa condição fisiológica, evitando desse modo o abortamento da inflorescência e, ao mesmo tempo, favorecendo o seu desenvolvimento. Da mesma forma, o maior NFFI também ocorreu em dezembro e março, o que pode ser explicado pela formação dos primórdios florais ter ocorrido cerca de um ano antes da abertura da inflorescência (Coomans, 1975), coincidindo com meses de pluviosidade atípica: dezembro de 2001(159,4 mm), janeiro de 2002 (239,8 $\mathrm{mm}$ ) e fevereiro de 2002 ( $87,6 \mathrm{~mm})$, já que são meses normalmente secos na região em estudo. Outro aspecto importante é que as temperaturas mais elevadas do período em que as cultivares apresentaram maior NFFI, favoreceram o desenvolvimento final das flores femininas e masculinas (Coomans, 1975). Lörh (1993), citado por Ohler (1999), também registrou alta quantidade de flores femininas, coincidindo com a estação quente e com as primeiras chuvas após um longo período seco.

A cultivar que apresentou o maior NIE, foi o AAM, sendo significativamente superior às demais cultivares em setembro e dezembro (Tabela 5). Embora o NIE do AAM tenha sido superior ao das demais cultivares na maior parte do período estudado, não diferindo significativamente do AVM e do $\mathrm{AVeBrJ}$ de março a setembro de 2003, o NFFI nessa cultivar foi inferior ao AVeBrJ na maior parte do período estudado (Tabela 6). Passos et al. (1999), ao avaliarem as cultivares AAM, AVM e AVeBrJ nas condições da planície litorânea também constataram maior NIE no AAM, no período seco. Assim, a maior emissão de inflorescência do AAM não indica que essa cultivar apresente posteriormente maior número de frutos. Do mesmo modo, o maior NFFI nem sempre proporciona o maior número de frutos, devido ao abortamento de flores femininas, principalmente nas inflorescências com mais de uma flor feminina na mesma espiga. Essa observação foi confirmada na cultivar AVeBrJ, que embora tenha apresentado um NFFI significativamente superior às demais cultivares em março, apresentou o NFr3, em junho, ligeiramente inferior ao AVC, não diferindo deste e sendo significativamente superior ao AAM e ao AVM (Tabela 7).

Seis meses após a abertura da inflorescência (setembro de 2003), não ocorreram diferenças no NFr6 entre as cultivares estudadas (Tabela 8). Esse fato mostra que, até aos três meses de idade, a perda de frutos é maior, por estes serem mais suscetíveis às adversidades climáticas, principalmente ao estresse hídrico, que pode ocorrer mesmo em plantios irrigados, devido à elevada demanda evaporativa nos meses mais secos e também por serem mais sensíveis ao ataque de pragas. Os dados aqui apresentados mostram uma tendência de maior NFr6 em dezembro, o que pode ser explicado pelo desenvolvimento inicial dos mesmos ocorrer nos meses em que a pluviosidade é mais elevada.

Os maiores valores de NFFIe NFr6 no AVeBrJ, em relação às demais cultivares, durante a maior parte do ano, embora em alguns períodos essa diferença não seja significativa (Tabelas 6 e 8), mostra que essa cultivar, além de ter maior freqüência de emissão de inflorescências e, conseqüentemente, maior número de cachos, apresenta, também, a maior capacidade de conservar seus frutos até $o$ ponto de colheita, mostrando-se mais adaptada ecologica e economicamente a esse ambiente. 
TABELA 1 - Composição química do solo da área experimental.

\begin{tabular}{|c|c|c|c|c|c|c|}
\hline $\mathrm{pH}$ em água & $\begin{array}{c}\mathrm{P} \\
\left(\mathrm{mg} \mathrm{dm}^{-3}\right)\end{array}$ & $\begin{array}{c}\mathrm{K} \\
\left(\mathrm{mg} \mathrm{dm}^{-3}\right)\end{array}$ & $\begin{array}{c}\mathrm{Ca} \\
\left(\mathrm{mmol}_{\mathrm{cdm}}{ }^{-3}\right)\end{array}$ & $\begin{array}{c}\mathrm{Mg} \\
\left(\mathrm{mmol} \mathrm{cdm}^{-3}\right)\end{array}$ & $\begin{array}{c}\mathrm{Al} \\
\left(\mathrm{mmol} \mathrm{cdm}^{-3}\right)\end{array}$ & $\begin{array}{c}\text { M.O } \\
\left(\mathrm{g} \mathrm{dm}^{-3}\right)\end{array}$ \\
\hline 5,94 & 8,52 & 41,89 & 11,7 & 5,4 & 0,9 & 125 \\
\hline
\end{tabular}

TABELA 2 - Número de folhas vivas (NFV) das cultivares de coqueiro-anão: anão amarelo da Malásia (AAM), anão vermelho da Malásia (AVM), anão vermelho de Camarões (AVC) e anão verde do Brasil de Jiqui (AVeBrJ), de junho de 2002 a setembro de 2003, no Platô de Neópolis-SE.

\begin{tabular}{ccccccc}
\hline Cultivares & Junho/02 & Setembro/02 & Dezembro/02 & Março/03 & Junho/03 & Setembro/03 \\
\hline AAM & $25,22 \mathrm{aB}$ & $26,63 \mathrm{aA}$ & $22,16 \mathrm{abD}$ & $23,56 \mathrm{aC}$ & $26,59 \mathrm{aA}$ & $27,09 \mathrm{aA}$ \\
AVM & $23,63 \mathrm{bB}$ & $24,81 \mathrm{bA}$ & $20,47 \mathrm{bcC}$ & $21,66 \mathrm{aC}$ & $24,38 \mathrm{bAB}$ & $24,72 \mathrm{bA}$ \\
AVC & $20,53 \mathrm{cBC}$ & $21,53 \mathrm{cAB}$ & $18,53 \mathrm{cD}$ & $19,44 \mathrm{bCD}$ & $21,75 \mathrm{cAB}$ & $22,41 \mathrm{cA}$ \\
AVeBrJ & $24,01 \mathrm{bBC}$ & $25,13 \mathrm{bAB}$ & $22,60 \mathrm{aD}$ & $23,31 \mathrm{aCD}$ & $24,91 \mathrm{bAB}$ & $25,94 \mathrm{abA}$ \\
\hline C.V. $(\%)$ & 1,61 & 1,73 & 4,20 & 3,94 & 2,52 & 2,44 \\
\hline
\end{tabular}

Médias seguidas de mesma letra, minúscula na coluna e maiúscula na linha, não diferem significativamente, pelo teste Tukey, a $5 \%$ de probabilidade.

TABELA 3 - Número de folhas mortas (NFM) das cultivares de coqueiro-anão: anão amarelo da Malásia (AAM), anão vermelho da Malásia (AVM), anão vermelho de Camarões (AVC) e anão verde do Brasil de Jiqui (AVeBrJ), de setembro de 2002 a setembro de 2003, no Platô de Neópolis-SE.

\begin{tabular}{cccccc}
\hline Cultivares & Setembro/02 & Dezembro/02 & Março/03 & Junho/03 & Setembro/0 \\
\hline AAM & $2,97 \mathrm{aB}$ & $9,47 \mathrm{aA}$ & $1,97 \mathrm{aBC}$ & $1,69 \mathrm{aC}$ & $2,13 \mathrm{aBC}$ \\
AVM & $2,25 \mathrm{bB}$ & $8,75 \mathrm{abA}$ & $2,00 \mathrm{aB}$ & $1,41 \mathrm{aB}$ & $1,91 \mathrm{aB}$ \\
AVC & $2,41 \mathrm{abB}$ & $7,22 \mathrm{bA}$ & $2,19 \mathrm{aB}$ & $1,63 \mathrm{aB}$ & $1,56 \mathrm{aB}$ \\
AVeBrJ & $2,44 \mathrm{abB}$ & $7,47 \mathrm{bA}$ & $2,72 \mathrm{aB}$ & $2,53 \mathrm{aB}$ & $1,22 \mathrm{aC}$ \\
\hline C.V. $(\%)$ & 10,37 & 8,44 & 15,54 & 46,53 & 24,55 \\
\hline
\end{tabular}

Médias seguidas de mesma letra, minúscula na coluna e maiúscula na linha, não diferem significativamente, pelo teste Tukey, a 5\% de probabilidade.

TABELA 4 - Número de folhas emitidas (NFE) das cultivares de coqueiro-anão: anão amarelo da Malásia (AAM), anão vermelho da Malásia (AVM), anão vermelho de Camarões (AVC) e anão verde do Brasil de Jiqui (AVeBrJ), de setembro de 2002 a setembro de 2003, no Platô de Neópolis-SE.

\begin{tabular}{cccccc}
\hline Cultivares & Setembro/02 & Dezembro/02 & Março/03 & Junho/03 & Setembro/03 \\
\hline AAM & $4,38 \mathrm{aB}$ & $5,00 \mathrm{aA}$ & $3,38 \mathrm{aC}$ & $4,72 \mathrm{aAB}$ & $2,63 \mathrm{aD}$ \\
AVM & $3,66 \mathrm{bB}$ & $4,41 \mathrm{bA}$ & $3,19 \mathrm{aC}$ & $4,13 \mathrm{bA}$ & $2,25 \mathrm{aD}$ \\
AVC & $3,41 \mathrm{bB}$ & $4,22 \mathrm{bA}$ & $3,09 \mathrm{aB}$ & $3,94 \mathrm{bA}$ & $2,22 \mathrm{aC}$ \\
AVeBrJ & $3,56 \mathrm{bC}$ & $4,94 \mathrm{aA}$ & $3,44 \mathrm{aC}$ & $4,13 \mathrm{bB}$ & $2,25 \mathrm{aD}$ \\
\hline C.V. $(\%)$ & 5,57 & 3,94 & 7,44 & 3,22 & 10,25 \\
\hline
\end{tabular}

Médias seguidas de mesma letra, minúscula na coluna e maiúscula na linha, não diferem significativamente, pelo teste Tukey, a $5 \%$ de probabilidade.

TABELA 5 - Número de inflorescências emitidas (NIE) das cultivares de coqueiro-anão: anão amarelo da Malásia (AAM), anão vermelho da Malásia (AVM), anão vermelho de Camarões (AVC) e anão verde do Brasil de Jiqui (AVeBrJ), de setembro de 2002 a setembro de 2003, no Platô de Neópolis-SE.

\begin{tabular}{cccccc}
\hline Cultivares & Setembro/02 & Dezembro/02 & Março/03 & Junho/03 & Setembro/03 \\
\hline AAM & $4,00 \mathrm{aC}$ & $5,28 \mathrm{aA}$ & $4,97 \mathrm{aAB}$ & $4,81 \mathrm{aB}$ & $1,88 \mathrm{aD}$ \\
AVM & $3,48 \mathrm{bB}$ & $4,69 \mathrm{bA}$ & $4,66 \mathrm{abA}$ & $4,31 \mathrm{aA}$ & $1,72 \mathrm{aC}$ \\
AVC & $3,45 \mathrm{bB}$ & $4,08 \mathrm{cA}$ & $4,25 \mathrm{bA}$ & $2,16 \mathrm{bC}$ & $1,66 \mathrm{aD}$ \\
AVeBrJ & $3,49 \mathrm{bB}$ & $4,59 \mathrm{bA}$ & $4,63 \mathrm{abA}$ & $4,72 \mathrm{aA}$ & $1,94 \mathrm{aC}$ \\
\hline C.V. $(\%)$ & 3,70 & 4,56 & 4,01 & 5,72 & 14,68 \\
\hline
\end{tabular}

Médias seguidas de mesma letra, minúscula na coluna e maiúscula na linha, não diferem significativamente, pelo teste Tukey, a $5 \%$ de probabilidade. 
TABELA 6 - Número de flores femininas por inflorescência (NFFI) das cultivares de coqueiro-anão: anão amarelo da Malásia (AAM), anão vermelho da Malásia (AVM), anão vermelho de Camarões (AVC) e anão verde do Brasil de Jiqui (AVeBrJ), de junho de 2002 a setembro de 2003, no Platô de Neópolis-SE.

\begin{tabular}{ccccccc}
\hline Cultivares & Junho/02 & Setembro/02 & Dezembro/02 & Março/03 & Junho/03 & Setembro/03 \\
\hline AAM & $28,34 \mathrm{bBC}$ & $26,06 \mathrm{bC}$ & $39,59 \mathrm{abA}$ & $37,94 \mathrm{bAB}$ & $22,97 \mathrm{bC}$ & $12,17 \mathrm{aD}$ \\
AVM & $30,94 \mathrm{abABC}$ & $26,41 \mathrm{bBC}$ & $37,91 \mathrm{bA}$ & $35,13 \mathrm{bAB}$ & $20,41 \mathrm{bCD}$ & $12,53 \mathrm{aD}$ \\
AVC & $35,70 \mathrm{aAB}$ & $26,41 \mathrm{bBCD}$ & $32,16 \mathrm{bBC}$ & $44,97 \mathrm{bA}$ & $22,47 \mathrm{bCD}$ & $16,17 \mathrm{aD}$ \\
AVeBrJ & $34,84 \mathrm{aC}$ & $32,88 \mathrm{aC}$ & $47,63 \mathrm{aB}$ & $94,28 \mathrm{aA}$ & $28,41 \mathrm{aC}$ & $14,56 \mathrm{aD}$ \\
\hline C.V.(\%) & 8,74 & 10,05 & 10,16 & 19,16 & 7,98 & 19,80 \\
\hline
\end{tabular}

Médias seguidas de mesma letra, minúscula na coluna e maiúscula na linha, não diferem significativamente, pelo teste Tukey, a $5 \%$ de probabilidade.

TABELA 7 - Número de frutos com três meses (NFr3) após a abertura da espata das cultivares de coqueiroanão: anão amarelo da Malásia (AAM), anão vermelho da Malásia (AVM), anão vermelho de Camarões (AVC) e anão verde do Brasil de Jiqui (AVeBrJ), de setembro de 2002 a setembro de 2003, no Platô de Neópolis-SE.

\begin{tabular}{cccccc}
\hline Cultivares & Setembro/02 & Dezembro/02 & Março/03 & Junho/03 & Setembro/03 \\
\hline AAM & $9,19 \mathrm{bA}$ & $8,00 \mathrm{bAB}$ & $6,00 \mathrm{bcBC}$ & $3,84 \mathrm{bC}$ & $10,64 \mathrm{aA}$ \\
AVM & $6,09 \mathrm{bAB}$ & $5,91 \mathrm{bAB}$ & $8,47 \mathrm{abA}$ & $4,69 \mathrm{bB}$ & $8,73 \mathrm{abA}$ \\
AVC & $14,21 \mathrm{aA}$ & $5,94 \mathrm{bC}$ & $5,43 \mathrm{cC}$ & $8,91 \mathrm{aB}$ & $7,00 \mathrm{bBC}$ \\
AVeBrJ & $7,11 \mathrm{bC}$ & $13,00 \mathrm{aA}$ & $10,56 \mathrm{aAB}$ & $7,56 \mathrm{aC}$ & $9,84 \mathrm{aBC}$ \\
\hline C.V. $(\%)$ & 17,37 & 19,96 & 16,39 & 17,21 & 10,46 \\
\hline
\end{tabular}

Médias seguidas de mesma letra, minúscula na coluna e maiúscula na linha, não diferem significativamente, pelo teste Tukey, a $5 \%$ de probabilidade.

TABELA 8 - Número de frutos com seis meses (NFr6) após a abertura da espata das cultivares de coqueiroanão: anão amarelo da Malásia (AAM), anão vermelho da Malásia (AVM), anão vermelho de Camarões (AVC) e anão verde do Brasil de Jiqui (AVeBrJ), de dezembro de 2002 a setembro de 2003, no Platô de Neópolis-SE.

\begin{tabular}{ccccc}
\hline Cultivares & Dezembro/02 & Março/03 & Junho/03 & Setembro/0天 \\
\hline AAM & $5,16 \mathrm{bA}$ & $3,19 \mathrm{bB}$ & $0,94 \mathrm{bC}$ & $1,19 \mathrm{aC}$ \\
AVM & $5,20 \mathrm{bA}$ & $4,50 \mathrm{bAB}$ & $2,87 \mathrm{abBC}$ & $1,88 \mathrm{aC}$ \\
AVC & $10,87 \mathrm{aA}$ & $4,01 \mathrm{bB}$ & $1,53 \mathrm{bC}$ & $2,78 \mathrm{aBC}$ \\
AVeBrJ & $5,48 \mathrm{bB}$ & $9,10 \mathrm{aA}$ & $4,00 \mathrm{aBC}$ & $2,75 \mathrm{aC}$ \\
\hline C.V. $(\%)$ & 9,55 & 22,66 & 44,54 & 39,84 \\
\hline
\end{tabular}

Médias seguidas de mesma letra, minúscula na coluna e maiúscula na linha, não diferem significativamente, pelo teste Tukey, a $5 \%$ de probabilidade.

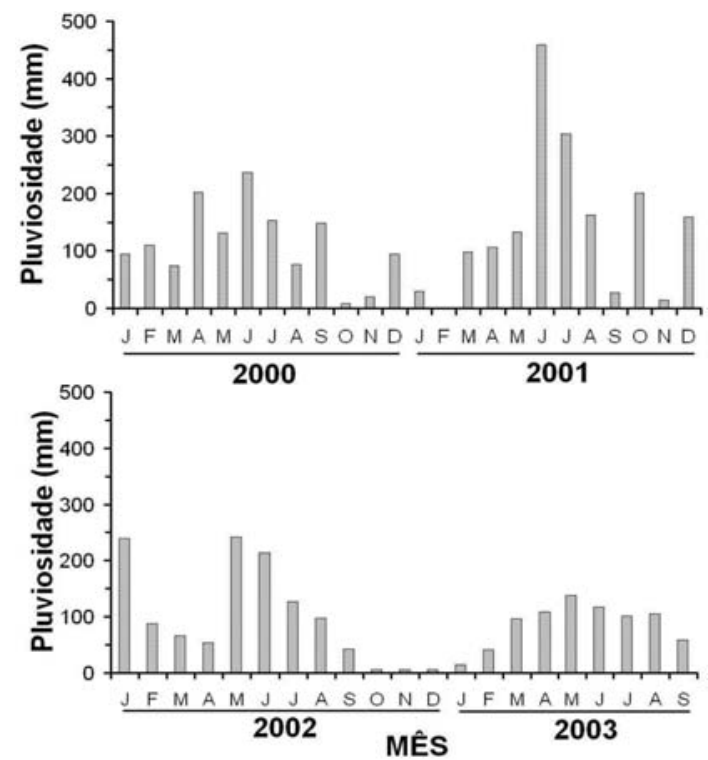

FIGURA 1- Pluviosidade no Platô de Neópolis-SE, durante o período de janeiro de 2000 a setembro de 2003. Ascondir. 


\section{CONCLUSÃO}

A floração das cultivares está relacionada a uma boa condição hídrica no momento de formação dos primórdios florais, sendo importante atender às necessidades hídricas do coqueiro através da irrigação nos períodos de baixa pluviosidade. Nas condições do Platô de Neópolis, AVeBrJ (Anão Verde do Brasil de Jiqui) apresenta floração e frutificação superiores às demais cultivares. A maior perda de rutos dá-se até o terceiro mês de desenvolvimento, quando os frutos são mais suscetíveis às adversidades ambientais.

\section{REFERÊNCIAS}

ANDERSON, A. B.; OVERAL, W. L.; HENDERSON, A. Pollination ecology of a forest-dominant palm (Orbignya phalerata Mart.) in Northern Brazil. Biotropica, Lawrance, v. 20, n. 3, p. 192-205, 1988.

CHILD, R. Coconuts. London: Longman, 1974. 335 p.

COOMANS, P. Influence des facteurs climatiques sur les fluctuations saisonnières et annuelles de la production du cocotier. Oléagineux, França, v. 30, n. 4, p. 153-159, 1975.

FREMOND, Y.;ZILLER, R.; LAMONTE, M. N. El cocotero: tecnicas agrícolas y producciones tropicales. Barcelona: Editorial Blume, 1975. 236 p.

OHLER, J. G. Modern coconut management: palm cultivations and products. London: FAO, 1999. 458 p.

OLIVEIRA, M. S. P.; COUTURIER, G.; BESERRA, P. Biologia da polinização da palmeira tucumã (Astrocaryum vulgare Mart.) em Belém, Pará, Brasil. Acta Botânica Brasilica, São Paulo, v.17, n. 3, p. 343-353, 2003.
PASSOS, E. E. M. Morfologia do coqueiro. In: FERREIRA, J. M. S.; WARWICK, D. R. N.; SIQUEIRA, L. A. A cultura do coqueiro no Brasil. 2.ed. Brasília: Embrapa Serviço de Produção e Informação, 1998. p.57-64.

PASSOS, E. E. M.; PRADO, C. H. B. A.; LEAL, M. L. S. Condutância estomática, potencial hídrico foliar e emissão de folhas e inflorescências em três genótipos de coqueiro anão. Agrotrópica, Ilhéus, v. 11, n. 3, p. 147-152, 1999.

PERSLEY, G. J. Replanting the tree of life: towards a international agenda for coconut palm research. Wallinggard: CABI/ACIAR, 1992. 156p.

SCARIOT, A. O.; LLERAS,E.; HAY, J. D. Reproductive biology of the palm Acrocomia aculeata in Central Brazil. Biotropica, Lawrence, v.23, n.1, p.12-22. 1991.

SILVA, M. C.; GAÍVA, H. N.; PEREIRA, W. E.; ARAGÃO, W. M. Crescimento e florescimento de uma cultivar anã e de quatro híbridos intervarietais de coqueiro, na região não-pantanosa de PoconéMT. Agropecuária Técnica, Areia, v.25, n.1.p. 13-23, 2004.

WOOD, P. J.; BURLEY, J. A tree for all reasons: introduction and evaluation of multipurpose trees for agroforestry. Nairobi, Kenya: Science and Practice of Agroforestry, 1991. 158p

WORLD BANK. Coconut production: present status and priorities for research. Washington: World Bank Technical Paper, 1991. 150p. 